\title{
Trabalho, Saúde e Meio Ambiente
}

\section{Work, Health and Environment}

Helenice Morais Sales ${ }^{1}$ Ilda Cecília Moreira da Silva ${ }^{2}$

\begin{abstract}
Resumo
$\mathrm{O}$ artigo trata da relação entre trabalho, saúde e meio ambiente demonstrando que dentre eles o trabalho se sobrepôe interferindo negativamente na saúde dos homens e de todo o planeta. Para se abordar o trabalho, inicia-se com a história das gens, grupamentos humanos da época da barbárie, relacionando seus fundamentos com a trajetória do trabalho em tempos mais recentes, ou seja, do século XIX aos nossos dias. O trabalho do qual se fala desenvolve-se no modo de produção capitalista, o qual tem priorizado o capital em detrimento da saúde do homem e da saúde do meio ambiente. Finalizando, uma reflexão é feita sobre a necessidade da mudança de paradigma deste modo de produção, no sentido dos interesses do capital não se colocarem acima dos interesses da saúde do planeta.
\end{abstract}

Pavavras-chave: trabalho, saúde, meio ambiente.

\section{Abstract}

The article treats about the relationship among work, health and environment showing that among them the work remains above interferring negatively in the human and planet health. Making an approach about work, we begin with gens history, human groups from the barbarian epoch, their conceptual basis with work trajectory in more recent time, let's say, from the nineteenth century to our present days. The work about which is spoken develops in the way of capitalist production, which has priorized the capital in detriment of human and environment health. At the end, a reflection is made about the necessary changing of paradigm of this production mode, in the sense of capital interests not being put above the planet health interests.

Keywords: work, health, environment. 


\section{INTRODUÇÃO}

Trabalho, saúde e meio ambiente são elos de uma mesma cadeia uns são influenciados e exercem influência sobre os outros.

O trabalho é a fonte de subsistência do homem, entretanto o próprio trabalho desgasta a saúde dos indivíduos, assim como, contraditoriamente, propicia condiçôes materiais para que a saúde seja restaurada possibilitando o retorno do trabalhador ao seu ofício, pois o sistema produtivo não pode ser prejudicado.

Da mesma forma que o trabalho, o meio ambiente concorre para a sobrevivência do homem, enquanto espaço natural e sócio-cultural. Esse meio ambiente que dá condiçóes de existência ao seres humanos, em contra partida, adoece, devido o tratamento inadequado que lhe é dispensado pela sociedade humana.

As concepções de meio ambiente, saúde e trabalho, as quais estabelecem a estrutura deste artigo, serão apresentadas a seguir.

Coriolano et al in Pimenta et al (orgs.) (2009) tecem comentários sobre o meio ambiente considerando-o não apenas traduzido pelas representaçôes naturais, mas também reconhecido como espaço social, cultural e político no qual interagem os homens com a natureza e os homens com os seus pares.

De acordo com o pensamento de Freire (2003) Saúde em sua amplitude penetra em todas as esferas das necessidades humanas: material, biopsíquica, psicossocial, sociopolítica, educacional, cultural.

A saúde, segundo a VIII Conferência Nacional de Saúde ocorrida em 1986, é resultante do trabalho, assim com, das condiçôes de alimentação, habitação, educação, renda, meio ambiente, lazer, liberdade, acesso a posse de terra e acesso a serviços de saúde. Todas as demais condiçóes postas pela referida Conferência são permeadas pelo trabalho, o qual, portanto, direta e indiretamente, tem relação com o meio ambiente e saúde em seu sentido amplo.

Caminhando mais detalhadamente pelo terreno do trabalho, segue uma citação que o revela:

“Trabalho: processo composto pela prévia ideação (...) [que é] a construção na consciência do resultado provável de uma determinada ação (...) e pela objetivação. Resulta, sempre, na transformação da realidade e, ao mesmo tempo, do indivíduo e sociedade envolvidos. (...) O trabalho funda o mundo dos homens; contudo a reprodução deste mundo, a sua história, apenas é possível pela gênese e desenvolvimento de relaçốes sociais que vão para além do trabalho enquanto tal. (...) E estas, por sua vez, precisam da mediaçáo de complexos como a ideologia, a filosofia, a arte, a educação, a sexualidade, a alimentação, o Estado,

o Direito, a Política, etc..." (LESSA, 1999, p. 22 e 32).

O trabalho apresenta uma longa história, a qual acompanha a trajetória da existência do homem, pois para sobreviver o homem lançou mão de sua prévia ideação e se pôs em ação na busca de alimentos e de abrigos.

\section{História das Gens}

Ao se rever a historia do trabalho humano não se pode deixar de ressaltar a história das gens.

As gens foram grupamentos humanos que existiram do estado selvagem à época da barbárie até a civilização e nos revelaram as suas divisóes do trabalho, de acordo com Engels (1981).

Algumas características das gens: nelas não existia internamente diferença entre direito e deveres; não permitiam divisão em diferentes classes sociais; a população ficava muito dispersa, só se concentrava no local de residência, ao redor da qual se estendia uma regiāo para caça e depois desta, havia uma zona neutra de bosques protetores que separavam as tribos uma das outras; a divisão do trabalho era espontânea e só existia entre os dois sexos. Cabiam à mulher os trabalhos domésticos e ao homem a caça, a pesca, a guerra; a economia doméstica era comum à várias famílias; tribos inteiras costumavam viver sobre o mesmo teto; a casa, a canoa, a horta eram de propriedade comum; uma tribo podia dividir-se em diversas gens. Uma Confederação unia as tribos aparentadas. Esta organização simples era capaz de resolver os conflitos nesta sociedade. Os conflitos externos eram resolvidos, através das guerras que podiam aniquilar a tribo adversária, mas nunca escravizá-la. A guerra era um mecanismo de proteção da tribo contra seus inimigos.

A primeira grande divisão social do trabalho ocorreu quando as tribos pastoras se destacaram do restante da massa dos bárbaros. Estas tribos produziram víveres em maior quantidade e variedade do que o resto dos bárbaros. Este fato tornou possível pela primeira vez, o intercâmbio regular dos produtos. Desta primeira grande divisão do trabalho, nasceu a primeira grande divisão da sociedade em duas classes: senhores e escravos; explorados e exploradores.

$\mathrm{Na}$ fase superior da barbárie ocorreu a segunda grande divisão do trabalho: o artesanato se separou da agricultura. O valor da força de trabalho do homem aumentou, em virtude do crescimento da produçáo e da produtividade do trabalho. A escravidão, nesta fase, tornou-se elemento básico do sistema social. A diferença entre livres e escravos passou a ser somada a diferença entre ricos e pobres.

A civilização acrescenta uma terceira divisão do trabalho, extremamente importante, ela inventa uma classe, a dos comerciantes, que não se ocupa da produção e sim, 
exclusivamente, da troca de produtos. A partir daí surgem os empréstimos e os juros. Convive ao lado da riqueza em dinheiro, em escravos e em mercadoria, a riqueza em terras.

O sistema gentílico chega ao seu final destruído pela divisão do trabalho que dividiu a sociedade em classes e estabeleceu o Estado.

Desde os estágios pré-históricos da cultura surge a divisão do trabalho e com ela a existência de explorados e exploradores; ricos e pobres; livres e escravos; proprietários de terras e os sem terras; artesãos e agricultores; comerciantes e não comerciantes. $\mathrm{O}$ Estado torna-se necessário para fazer as mediaçóes às estas forças antagônicas.

\section{MODO DE PRODUÇÃO CAPITALISTA}

A expropriação dos meios de produção dos produtores diretos, ou seja, dos trabalhadores existe desde essa época dos gentios e foi o veio condutor do desenvolvimento da produção capitalista, constituindo condição prévia para referida produção.

O trabalhador quando vende sua força de trabalho, fornece o resultado da mesma posta em ação para quem lhe comprou tal força.

"O comprador de sua capacidade de trabalho pode obrigá-lo a continuar trabalhando mesmo depois de ele ter criado um valor correspondente ao de sua força de trabalho, quando então produzirá um valor excedente ou uma "maisvalia”. (SANDRONI, 1999, p. 65).

$\mathrm{Na}$ perspectiva de se considerar a relação trabalho e meio ambiente, e os impactos sofrido por ambos no modo de produção capitalista, considera-se a seguinte afirmação:

"O modo de produzir e de consumir tem a natureza como recurso, portanto reduziu-a a imagem de mercadoria, degradando-a até a exaustão, fazendo emergir, na pauta das discussôes mundiais, as questôes relativas à (in) sustentabilidade. Para o imaginário moderno, a natureza existe para ser dominada pelo homem, para servir às suas finalidades, mesmo que acabe por comprometer a própria sobrevivência. (...) Sustentabilidade significa política e estratégia de desenvolvimento econômico, social e cultural contínuos, sem prejuízo do ambiente (inclusive dos recursos naturais) e do homem." (Coriolano, Leitão e Vasconcelos in CORRÊA E PIMENTA, 2009, p. 39 e 42).

Retomando a história do trabalho e passando das gens, as quais apresentam as bases do trabalho humano, aos tempos mais recentes correspondentes à periodização histórica do capitalismo, será exposto a este respeito o que escreve Mandel (1982). Para este autor os períodos do capitalis- mo são distribuídos entre: o período concorrencial, a partir de 1848, marcado pela revolução do vapor; o período do imperialismo clássico, final do século XIX até a década de 1930 que se configura pela monopolização do capital; o capitalismo tardio ou maduro, cujo período corresponde o intervalo de tempo entre o final da Segunda Guerra Mundial aos dias atuais, caracteriza-se pela automação, encurtamento do tempo de rotação do capital e intervenção estatal no controle do capital.

Os avanços tecnológicos marcaram as mudanças de estágios do capitalismo, os quais ampliaram, ilimitadamente, a produção, sofisticaram o controle sobre administração da mão de obra e propiciaram a criação de estratégias de acúmulo do capital.

\section{CONSIDERAÇÓES FINAIS}

Trabalho, Saúde e Meio Ambiente, estes três termos se completam e se chocam, e fornecem elementos para a sobrevivência humana e do planeta terra. Dentre eles, o trabalho tem se destacado como um elemento que se sobrepóe à saúde ao meio ambiente, interferindo negativamente nos mesmos.

Desde a época das gens, em seus estágios mais avançados, quando surge a divisão entre escravos e senhores, ricos e pobres, o homem para sobreviver necessita vender a sua força de trabalho e se submeter às imposiçóes dos donos dos meios de produção. Esta mesma dinâmica vem ocorrendo entre países ricos e pobres, os segundos ficam submetidos às decisóes dos primeiros. Assim como os países se subdividem, segundo suas riquezas, os homens são, também, classificados de acordo como seu poder econômico, sob o domínio do modo de produção capitalista.

Como o único bem do trabalhador é a sua força de trabalho expressa pelo seu corpo, este necessita ser saudável para poder produzir.

Segundo Minayo (1986), no modo de produção capitalista, o assalariamento faz do corpo "força de trabalho", criador de excedentes para as classes que detêm os meios de produção e única condição para sobrevivência do trabalhador e de sua família. De acordo com a referida autora, ainda, saúde e luta das classes trabalhadoras envolvem direitos sociais, representação da saúde como direito coletivo; implica, também, em transformaçôes no modo de produção e nas relaçôes sociais.

Ter saúde é pré-condição para assumir o trabalho, embora o trabalho possa provocar doença no indivíduo, como, também no meio ambiente.

Com a finalidade de tratar da saúde do planeta no que se refere à questáo climática, foi instalada em dezembro de 2009 a Conferência de Copenhague e nela o Brasil propõe 
que os países ricos ajudem, em termos econômicos, os países pobre e os países em desenvolvimento no combate aos efeitos indesejáveis da emissão de gases, os quais, crescentemente, vêm afetando negativamente a saúde do planeta terra.

Há grande expectativa no sentido de que, pelo ao menos, acordos políticos sejam fechados na Conferência de Copenhague e que em breve tempo eles sejam regulamentados. Os embates e impasses deste evento têm como cenário o modo de produção capitalista e a sua lógica: a divisão dos países e dos cidadãos entre ricos e pobres.

Retomando o pensamento de Minayo exposto anteriormente, o futuro da saúde do planeta e dos seus habitantes, implica nas transformaçôes do modo de produção capitalista e nas mudanças nas relaçóes sociais. Para tal uma nova visão de mundo necessita ser cultivada, na qual novos valores deverão emergir para que um novo paradigma se estabeleça, qual seja: na ordem mundial, o fator econômico abrir a possibilidade de se retrair e ceder espaço de forma humana, racional e consciente para o dialogo com as demais necessidades e demandas do planeta sabendo priorizálas quando for preciso, em detrimento de sua avidez pelo lucro e pela inconseqüente acumulação do capital.

\section{REFERÊNCIAS BIBLIOGRÁFICAS}

1. CORRÊA, M. L., PIMENTA S. M. e ARNDT, J. R. (orgs). Turismo, sustentabilidade e Meio Ambiente - contradiçôes e convergências. Belo Horizonte: autêntica Editora, 2009.

2. ENGELS, Friedrich. A Origem da Família, da Propriedade Privada e do Estado. Rio de Janeiro:Civilização Brasileira, 1981.

3. FREIRE, Lúcia M. B. O Serviço Social na Reestruturação Produtiva. São Paulo: Cortez Editora, 2003.

4. LESSA, Sérgio. O processo de produção / reprodução social: trabalho e sociabilidade, in:Capacitação em Serviço Social e Política Social, Módulo02. Brasilia: UnB, Centro de Educação Aberta, Continuada a Distância, 1999.

5. MINAYO, Maria Cecília de Souza. O Desafio do Conhecimento, São Paulo, Rio de Janeiro, HUCITEC ABRASCO, 2000

6. .MINISTÉRIO DA SAÚDE - histórico, conceitos e propostas. 8a Conferência Nacional de saúde, 17 a 21 de março de 1986. (www.google.com.br. - 27/07/2009).

Endereço para Correspondência:

Helenice Morais Sales - hmosales@ig.com.br Centro Universitário de Volta Redonda - UniFOA Av.Lucas Evangelista de Oliveira Franco, no 862 Aterrado - VR - RJ - Brasil

CEP: $27215-530$ 